\title{
Indian Anti-Malaria OMARIA Is Effective against African Drug Resistant $P$. falciparum Field Isolates and Laboratory Strains; without Toxicity*
}

\author{
Jean Bernard Lekana-Douki ${ }^{1}$, Deepak Bhattacharya ${ }^{2 \#}$, Rafika Zatra ${ }^{1}$, Fousseyni S. Toure-Ndouo ${ }^{1}$ \\ ${ }^{1}$ Unité de Parasitologie Médicale (UPARAM), Centre International de Recherches Médicales de Franceville (CIRMF), Franceville, \\ Gabon; ${ }^{2}$ Oddisi Research laboratory, Bhubaneswar, India. \\ Email: \#oddisilab1@dataone.in
}

Received October $11^{\text {th }}, 2011$; revised November $9^{\text {th }}, 2011$; accepted December $12^{\text {th }}, 2011$

\begin{abstract}
OMARIA which is used to treat malaria in Odisa province, India, was investigated in Africa. The in-vitro anti-malarial activity of OMARIA was tested on P. falciparum strains FCB (chloroquine-resistant) and 3D7 (chloroquine-sensitive) and on fresh clinical isolates from Gabon, using the DELI method. Host cell toxicity was analysed with the MTT test. Interesting activity was observed. Inhibition concentrations $\left(\mathrm{IC}_{50}\right)$ were $20.6 \pm 5.2 \mu \mathrm{g} / \mathrm{ml}$ and $14.1 \pm 4.3 \mu \mathrm{g} / \mathrm{ml} \mathrm{respect-}$ tively on FCB and 3D7 strains. On clinical isolates, the mean of $\mathrm{IC}_{50}$ was $10.65 \pm 4.8 \mu \mathrm{g} / \mathrm{ml}$. OMARIA is highly potent against all field isolates tested by us (Gabon includes Pfmdr1 N86). Lethal dose on Vero cells being $165 \pm 10.7 \mu \mathrm{g} / \mathrm{ml}$ indicate a selective index of 13 for FCB, i.e., non-toxic. Data substantiates scientific rationale for use of OMARIA. This information and such understanding can be used in searching African phyto parables (for use in Africa with similar results as in India) and in new drug design. With Indian assistance, Punica granatum can also be cultivated in Central Africa, and OMARIA can be made, with an aim to Fight Malaria at Home.
\end{abstract}

Keywords: Fruit Extracts; OMARIA; Antiplasmodial Activity; Asia-Africa Efficacy; Cytotoxicity; Drug Resistant-Field Isolates; Plasmodium Falciparum

\section{Introduction}

Malaria remains the most prevalent parasite disease killing around 781,000 patients in the world currently [1]. Malariologists are unanimous that vaccine is yet far off [2] and conventional treatment is chemotherapy with antimalarial drugs. But, emergence and rapid spread of antimalarial resistance parasites is the main obstacle. Hence, discovery of new antimalarial compound is urgently needed. Since the two best conventional antimalarial drugs (artemisinin and quinine) are extracted from plants, traditional medicine could bring solutions in the war against malaria. Several plants have been shown to possess strong antiplasmodial activity, for review see [3]. Several families of phytochemical compounds have antimalarial activity, including alkaloids, terpenes, quassinoids, flavonoids, limonoids, chalcones, xanthones and quinoleines [4,5]; racemic/toxic, synthetic spiroazepineindole derivatives [6]. Some have confounding and/or confabulating moieties; others have xenobiotic and/or unacceptable toxic effects at the blood-brain and/or at the

\footnotetext{
"There are no conflicting interests.
}

"Corresponding author. placental barrier; while some are unstable and or have other undesirable effects and/or require high doses. This apart, new drug development also mandates safety; prophylactic role; broad spectrum efficacy, and non pro inflammation. India \& China have more than a millennia old history of traditional-ethnic medicine and settled civilisation with ethnic natives. Chinese school of medicine has in the west been in focus for quite some time now, while the Indian components relatively, less. India is a geographically large democratic nation with a population behemoth of $\sim 1.2$ Billion (unique host bio-mass). It has an extensive health service system and sustained internal funding. We therefore, look onto India for fresh new lead. We find, therein, OMARIA is a home grown remedy that is being used to Fight Malaria at Home [7-9]. OMARIA is made from Punica granatum, a fruit of the member of Lythraceae family (synonymous of Punicaceae). This fruit is known as "dalimba" in Sanskrit (Indian national language). It yields the long acting ellagitanins and are non-chemotherapy compounds. OMARIA, which is ultra economic, uses them for anti-malaria purposes for the first time [10]. Non-chemotherapy route has been shown to be very expensive, as compared to che 
motherapy [11]. Thus, OMARIA is a paradigm shift among anti-malarial available candidates. Hence, is relevant for Africa.

The use of OMARIA started in June 1998 as a mini food based economic remedy for rural homes and went on to find large scale frank clinical application from June 1998 by the Indian Red Cross Society Ayurveda Dispensary, Koraput, Odisha, India- $18^{\circ} 49^{\prime} \mathrm{N} / 82^{\circ} 43^{\prime} \mathrm{E}$ (Figure $\mathbf{1}$, marked as $\mathrm{KD} / \mathrm{OC}$ ) under the aegis of District Magistrate cum Collectorate; under banner-"Fight Malaria at Home" [12]. During this period, $>15,000$ cases of therapy and $>1000$ case of prophylaxis has been under taken; operations are current (Bhattacharya, 2011). Figure 1 is that of the Indian sub-continent, with the province of Odisha marked on its eastern sea board. $\mathrm{KD}=($ Koraput district $), \& \mathrm{OC}=($ OMARIA clinic/centre $)$.

Interestingly, OMARIA is composed only of ellagic acid and a pair of tannins. These moieties are non alkaloids/non chemo. Hence, OMARIA offers a paradigm shift in anti-malarial management concept on pharmacological basis. In-vitro aspects of this green bio-medicine has been partly studied by multi lateral teams $[13,14]$; including in-vitro tests on W2 - the Asian drug resistant strain. OMARIA is also remarkably effective and safe $[15,16]$. However, neither OMARIA nor elagitanins have been studied against filed isolates (specially against drug resistant types) neither vis-à-vis Asian nor African strains (and either strains differ). Therefore, we elect to report OMARIA's efficacy against African (Gabonese) field isolates which is known for remarkable drug resistance, diversity and polymorphism. Moreover $\mathrm{KD} / \mathrm{OC}$ is located in the Tropic of Cancer, coastal belt facing a cyclone prone eastern shore board of subcontinental length. And, Franceville $\left(1^{\circ} 38^{\prime} \mathrm{S} / 13^{\circ} 35^{\prime} \mathrm{E}\right)$ is located in the Equatorial coastal belt facing a cyclone safe western shore board of the largest continent and is Doldrums region (marked as LV in Figure 2). The geographical domains; the geomorphology and the agrometeorological conditions of the Indo-African centre pairs offer as much contrast. Furthermore, Africa offers numerous phyto sources that indicate anti-plasmodial activity. Ellagitannin containing phyto sources have also not been focused upon, this far, in African context. Our model will posit as a referral tool cum platform for compare and contrast.

Since $P$. falciparum has the highest diversity and po-

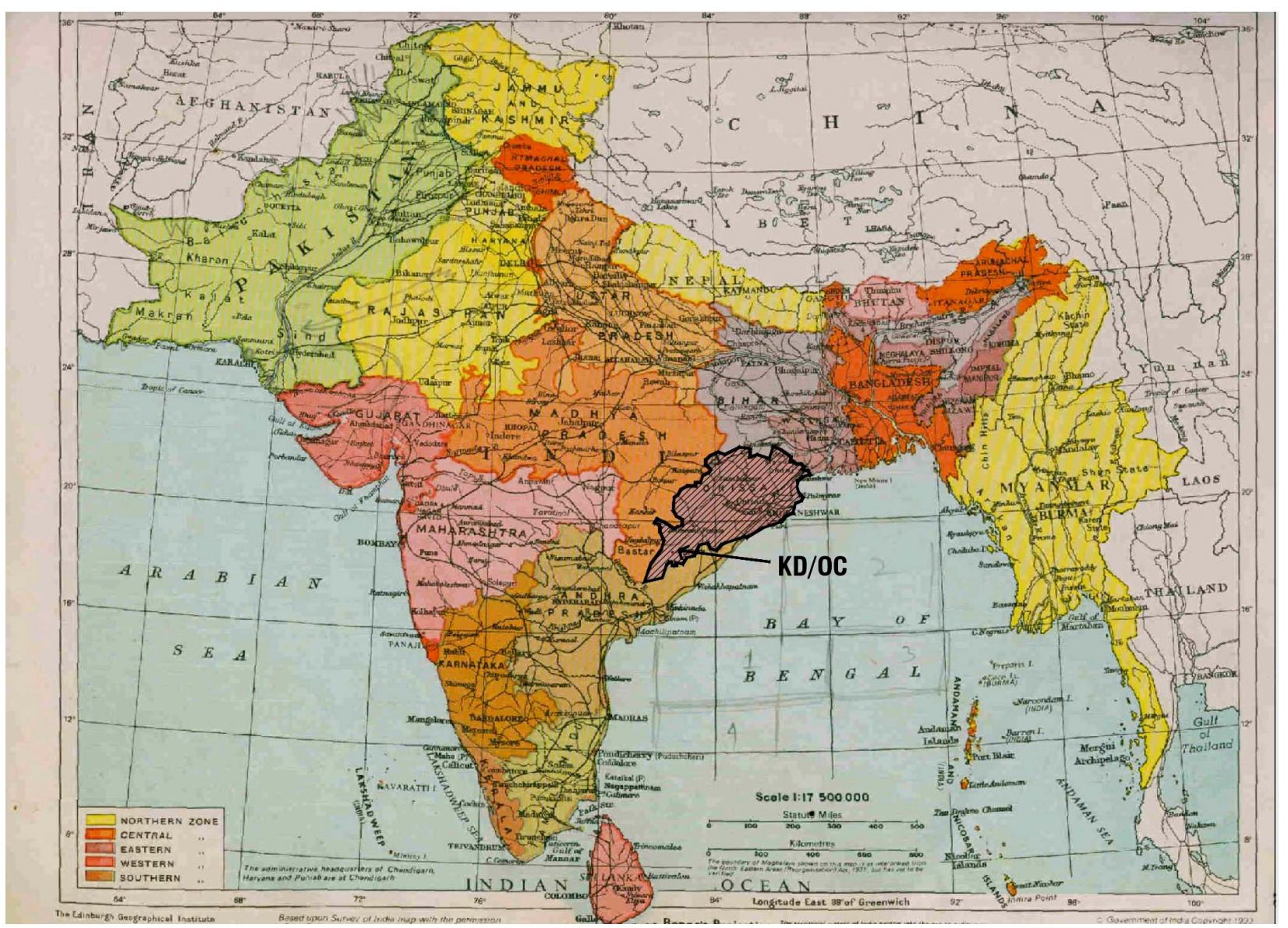

Figure 1. Geographic domain of Asia (India) use. KD/OC = Koraput District/Omaria Centre. 


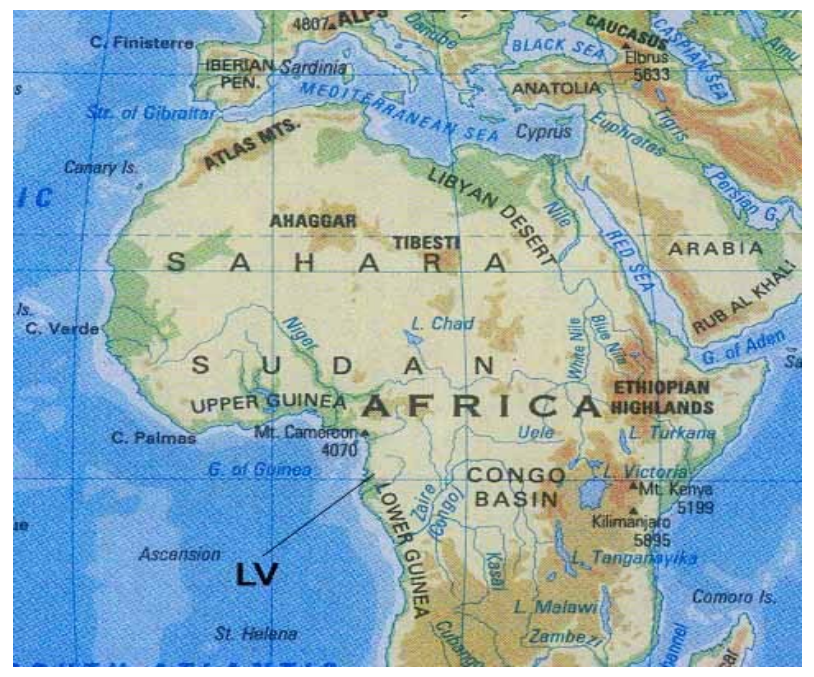

Figure 2. Geographic domain of African field isolates. LV = Libreville, Gabon.

lymorphism, it is necessary to test potential antiplasmodial compounds in diverse endemic regions (numerous continents specially). Therefore, it becomes necessary to use the authentic Indian source to evaluate efficacy against well identified \& fully characterised African-field isolates. Franceville is located in the south eastern Gabon, where malaria transmission is hyperendemic and perennial [17]. It is a high antimalarial resistance area [15]. Since 2005 national antimalarial policy has changed from chloroquine to artemisinin based combination therapies (ACTs). The main ACT that is used (as advised by the new national antimalarial policy) be Artemether-Lumefantrine, thus some changes has been observed including a decrease in $P$. falciparum prevalence and an increase in the prevalence of $P f m d r 1$ N86 genotype which are associated with drug resistance [19]. These changes suggest an adaptation of parasite arising out of the new national antimalarial policy. In India, Artemether-Lumefantrine (relatively more toxic) is not part of Govt., propelled policy, although this and similar ACTs are propelled by the commercial sectors. In India, drug resistance of malariasis \& its prevalence has (also) been stated to be high [20]; also having Pfmdr1 N86, including Odisha [21]. So, the aim of this study was to analyse the in vitro antiplasmodial activity of OMARIA against drug resistant laboratory strains FCB \& Chloroquine susceptible laboratory strain 3D7 and clinical isolates (field) from Gabon and also evaluate toxicity aspect.

\section{Materials and Methods}

\subsection{OMARIA Making}

OMARIA is made from Punica granatum (Ty-iii-only). It is of $<3.5 \mathrm{~cm}$ in diameter (Figure 3). The fruit is plucked at chloroplast stage. It is cut. The aril is discarded. The rind is bone dried in sun till stone hardness. It is then manually pounded to fine powder. Figure 4 gives a view of the thick rind.

\subsection{Plant Material and Extraction}

OMARIA ethanolic extracts were prepared by macerating $100 \mathrm{~g}$ of dried rind's powder with $500 \mathrm{ml}$ of ethanol at room temperature about $24 \mathrm{~h}$. Furthermore, the mixture was filtrated. The filtrates were evaporated to dryness under reduced pressure with a rotary evaporator $\left(\right.$ Rotavapor $^{\circledR}$ ) at $30^{\circ} \mathrm{C}$.

\subsection{Parasite Culture}

P. falciparum strains 3D7 (CQ-sensitive) and FCB

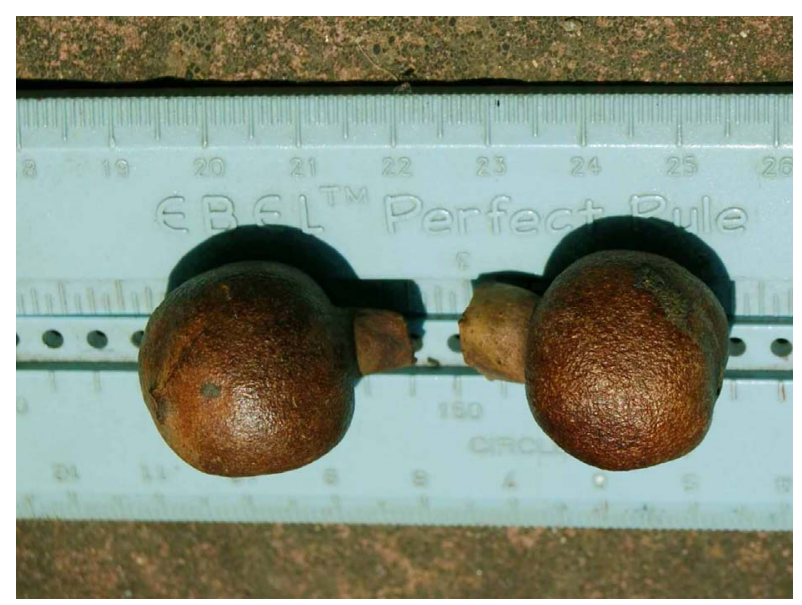

Figure 3. Punica granatum, sun dried whole fruit.

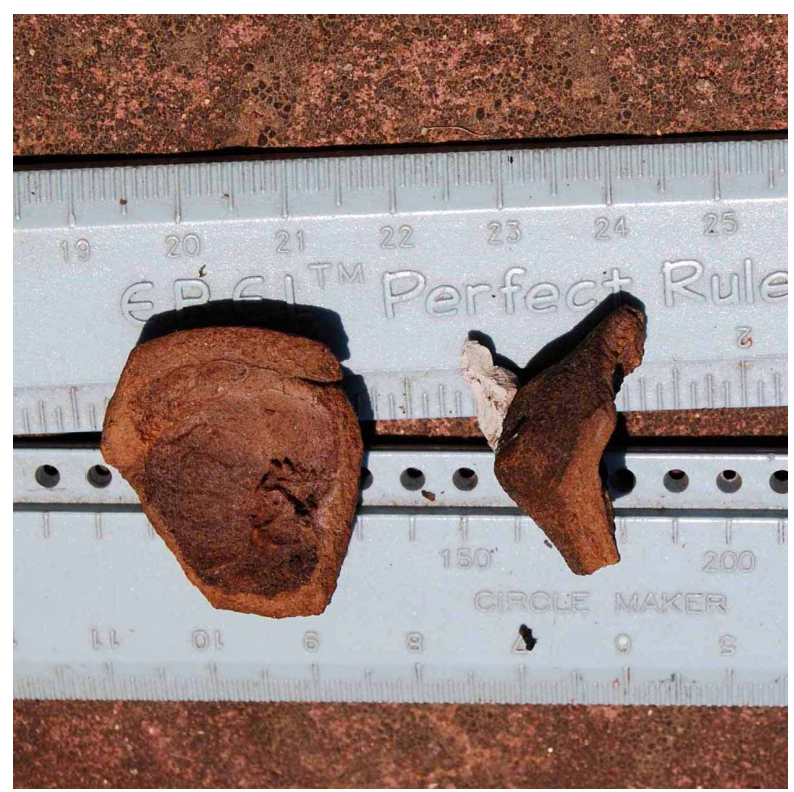

Figure 4. Cut section of punica, showing thick rind. 
(CQ-resistant) obtained from MR4 ${ }^{\circledR}$ (Malaria Research and Reference Reagent Resource Center) were cultured in standard conditions [22]. Parasites were synchronized by repeated $5 \%$ sorbitol treatment. OMARIA extracts were dissolved in DMSO at an initial concentration of $200 \mathrm{mg} / \mathrm{ml}$ and serially diluted with culture medium before being added to synchronous parasite cultures. Two hundred (200) microliters of synchronised trophozoite suspension $(1.5 \%$ final hematocrit in RPMI 1640 medium $+0.5 \%$ Albumax $^{\circledR}$ ) was incubated with each concentration of the plant extracts in 96-well flat-bottom plates (NUNC, VW International, Strasbourg, France) at $37^{\circ} \mathrm{C}$ for $42 \mathrm{~h}$, as previously described [23].

\subsection{Field Isolates}

Field isolates were collected from the patients (after informed consent) between May to July 2010. Ethical clearance and national endorsement were received from the Gabonese Ministry of Health. Three to five milliliters (3 - $5 \mathrm{ml}$ ) of blood was collected in an EDTA tube, and malaria was diagnosed with the Lambaréné blood smear method [24] with a cutoff of more than 1000 parasites $/ \mu \mathrm{L}$. Dihydroartemisinin (DHA) and Chloroquine (CQ) was used as control. According to previous data, isolates were considered resistant against $\mathrm{CQ}$ and DHA when their $\mathrm{IC}_{50}$ were respectively higher than $100 \mathrm{nM}$ and $10 \mathrm{nM}$.

\subsection{Antiplasmodial Activity}

Antiplasmodial activity was analyzed by colorimetric essay based on pLDH measurement as previously described [25]. The $\mathrm{IC}_{50}$ (drug concentration that reduced parasitemia by $50 \%$ ) was calculated as the mean of 3 independent experiments.

\subsection{Cytotoxicity Assay}

The cytotoxicity of the extracts was evaluated on MRC-5 human diploid embryonic lung cells, by using the MTT tetrazolium salt (3-(4,5-dimethylthiazol-2-yl)-2,5-diphenyltetrazolium bromide (Sigma ${ }^{\circledR}$, Germany) colorimetric method as previously described [26]. Cytotoxicity was scored as the percentage reduction of absorbance at 570 $\mathrm{nm}$ in treated cultures versus control cultures (contained medium culture only). The $50 \%$ lethal dose $\left(\mathrm{LD}_{50}\right.$, the drug concentration that reduced the number of viable cells by $50 \%$ ) was calculated as the mean of 3 independent experiments.

\subsection{Selectivity Index}

The selectivity index (SI), corresponding to the ratio between cytotoxic and antiparasitic activities, was calculated as follows

$$
\mathrm{SI}_{\text {Plasmodium }}=\left(\mathrm{LD}_{50 \text { Anthropo }}\right) \div\left(\mathrm{IC}_{50 \text { Plasmodium }}\right) \text {. }
$$

\section{Results}

We investigated the in vitro activity of ethanolic extracts of OMARIA against both CQ sensitive (3D7) and resistant strains (FCB). Table 1 show that OMARIA exhibited a good plasmocidal activity range between $8.2 \pm 3.5$ and $12.5 \pm 6.4 \mu \mathrm{g} / \mathrm{ml}$. Its toxicity was nil $\left(\mathrm{LD}_{50}=165 \pm\right.$ $3.5 \mu \mathrm{g} / \mathrm{ml}$ ) giving a high antiplasmodial selectivity index (SI) ranged between 13.3 and 20.2 respectively for FCB and 3D7 strains.

Furthermore, OMARIA extracts were tested against 16 field isolates from Franceville (Table 2). The $\mathrm{IC}_{50}$ was ranged between $5.1 \pm 0.2$ and $21.7 \pm 8.5 \mu \mathrm{g} / \mathrm{ml}$, with a mean of $10.65 \pm 4.8$. It suggests that OMARIA is active against Gabonese $P$. falciparum isolates. The $\mathrm{IC}_{50}$ of $\mathrm{CQ}$ against the tested isolates ranged between 3.4 to 375.2 $\mathrm{nM}$. CQ is most potent against isolates 21351, 21632 and 21710 with $\mathrm{IC}_{50}$ of $3.4,3.6$ and 7.8 respectively. The prevalence of CQ resistant isolates found was $50 \%$ and OMARIA is highly active against all the CQ resistant and sensitive isolates.

If we contrast isolates No. 21716 and 21723, we note that OMARIA exhibited high activity against both isolates $(6.8$ and $7.3 \mu \mathrm{g} / \mathrm{ml})$ despite 21716 being CQ-resistant phenotype. Now, 21716 is $\mathrm{CQ}$ resistant $\left(\mathrm{IC}_{50}=\right.$ $375.2 \mathrm{nM})$; whereas 21723 is CQ sensitive $\left(\mathrm{IC}_{50}=60\right.$ $\mathrm{nM})$. Of the 16 sample range, only one (21680) of the tested isolates showed an $\mathrm{IC}_{50}$ higher than $10 \mathrm{nM}$ against DHA. Interestingly, OMARIA exhibited high activity against this isolate, too.

Again, over the 16 isolates, the resistance range of CQ is of the range 3.4 to 375.2 that equals to an order of

Table 1. In vitro antiplasmodial activity, cytotoxicity and selectivity index of ethanolic extract of OMARIA.

\begin{tabular}{|c|c|c|c|c|c|c|}
\hline & & \multirow{2}{*}{\multicolumn{2}{|c|}{ Antiplasmodial activity }} & \multirow{2}{*}{ Cytotoxicity MRC-5 } & \multirow{2}{*}{\multicolumn{2}{|c|}{ Selectivity Index ${ }^{c}$}} \\
\hline \multicolumn{2}{|c|}{ Extract } & & & & & \\
\hline & & FCB & 3D7 & $\left(\mathrm{LD}_{50}, \mu \mathrm{g} / \mathrm{ml}\right)^{\mathrm{b}}$ & FCB & 3D7 \\
\hline OMARIA & $\mathrm{EtOH}$ & $12.5 \pm 6.4$ & $8.2 \pm 3.5$ & $165.9 \pm 10.7$ & 13.3 & 20.2 \\
\hline
\end{tabular}

${ }^{\mathrm{a}} \mathrm{IC}_{50}$ the drug concentration that reduced parasitemia to $50 \%$; ${ }^{\mathrm{b}} \mathrm{LD}_{50}=$ the drug concentration that reduced the number of viable cells by $50 \%$; ${ }^{\mathrm{c}} \mathrm{Selectivity}$ index $=$ Ratio $\mathrm{LD}_{50} / \mathrm{IC}_{50} . \mathrm{FCB}=P$. falciparum chloroquine-resistant strain. $3 \mathrm{D} 7=$ P. falciparum chloroquine-sensitive strain. 
110.35 times. The range of DHA (for the same isolates)is between 0.1 to 11.1 equaling to an order of 111 (similar efficacy range). The mean/average resistance of the Gabonese field isolates to CQ is 3.38 times more than DHA $(10.65 \div 2.81)$. CQ is most potent against isolate No. $1 \&$ 6 (near equally). The same two isolates are $11.3 \& 1.8$ times more sensitive to DHA, respectively. Yet, DHA is 3 times more potent against isolate No. 14 than what it is against isolate No.1 (against which CQ has the highest efficacy). Whereas, for OMARIA the sensitivity difference between No. $1 \& 14$ is only of the order $<50 \%$. If we contrast the efficacy of CQ as in isolate No. 13 \& with that of DHA as in isolate No. 14., we note that isolate No. 13 is 3752 more resistant. While, CQ is least potent against isolate No. 13, DHA is least effective against isolate No. 10 . So, there is no linearity between CQ \& DHA as regards potency/sensitivity vis-à-vis any isolate. In other words, non-linear, (even stark) variability is the hall mark of our sample isolate group (individual specific). If we consider isolate No. $9 \& 13$ we note that between CQ's and OMARIA's performance there exists no linear relationship. Finally, we note that OMARIA has no cytotoxicity.

The swing between maximum and minimum sensitiveity (Table 3$)$ in case of OMARIA is $(2.08 \times 2.03) 4.22$ times. For DHA it is $(3.95 \times 28.1) 110.1$, and for CQ it is $(3.47 \times 31.8) 110.34$. Figure 5 articulates it in cartograph form.

Figure 5 (drawn on the basis of Table 2) helps us to also appreciate that OMARIA which is raw extract (and

Table 2. Antiplasmodial activity in field isolates.

\begin{tabular}{|c|c|c|c|c|c|}
\hline \multirow{2}{*}{ Sl. No. } & \multirow{2}{*}{ Number of Isolates } & \multirow{2}{*}{$\frac{\mathrm{IC}_{50} \pm \mathrm{SD}(\mu \mathrm{g} / \mathrm{mL})}{\text { OMARIA (EtOH) }}$} & \multicolumn{2}{|c|}{$\mathrm{IC}_{50} \pm \mathrm{SD}(\mathrm{nM})$} & \multirow[t]{2}{*}{ Pfmdr1 N86 } \\
\hline & & & DHA & CQ & \\
\hline 1 & 21351 & 6.5 & $0.3 \pm 0.1$ & 3.4 & N86 \\
\hline 2 & 21337 & 5.1 & $0.6 \pm 0.2$ & 110 & Y86 \\
\hline 3 & 21424 & 8.9 & $4.8 \pm 1.0$ & 107.7 & Y86 \\
\hline 4 & 21523 & 12.7 & $5.8 \pm 0.8$ & 143 & N86 \\
\hline 5 & 21522 & 15.6 & $0.9 \pm 0.2$ & 100 & N86 \\
\hline 6 & 21632 & 10.9 & $2.0 \pm 0.5$ & 3.6 & Y86 \\
\hline 7 & 21667 & 14.2 & $0.6 \pm 0.3$ & 212.8 & Y86 \\
\hline 8 & 21672 & 10 & $5.9 \pm 1.8$ & 183.8 & N86 \\
\hline 9 & 21674 & 21.7 & $6.4 \pm 1.1$ & 278.5 & Y86 \\
\hline 10 & 21680 & 7.3 & $11.1 \pm 1.7$ & 29.5 & N86 \\
\hline 11 & 21681 & 10.7 & $1.0 \pm 0.4$ & 70.6 & Y86 \\
\hline 12 & 21710 & 6.6 & $1.9 \pm 0.4$ & 7.8 & N86 \\
\hline 13 & 21716 & 6.8 & $1.0 \pm 0.3$ & 375.2 & Y86 \\
\hline 14 & 21723 & 7.3 & $0.1 \pm 0.2$ & 60 & Y86 \\
\hline 15 & 21745 & 18.6 & $0.6 \pm 0.2$ & 17.9 & Y86 \\
\hline 16 & 21769 & 7.5 & $2.1 \pm 0.6$ & 26.6 & N86 \\
\hline
\end{tabular}

Note: Total 16 isolates. CQ's $\mathrm{IC}_{50}$ value that are 100 and above are resistant strains. $\mathrm{DHA}$ 's $\mathrm{IC}_{50}$ value that are 10 and above are similarly resistant (to DHA only). Isolates collected at the pediatric unit of hospital at Liberville.

Table 3. Sensitivity swing.

\begin{tabular}{|c|c|c|c|}
\hline Max. Resistance & 21.7 & 11.1 & 375.2 \\
\hline Average Sensitivity & 10.65 & 2.81 & 108.15 \\
\hline \multirow[t]{2}{*}{ Maximum Sensitivity } & 5.1 & 0.1 & 3.4 \\
\hline & OMARIA & DHA & CQ \\
\hline Swing from Average & $2.08 \leftrightarrow(-) 2.03$ & $3.95 \leftrightarrow(-) 28.1$ & $3.47 \leftrightarrow(-) 31.8$ \\
\hline
\end{tabular}

Ratio $\mathrm{IC}_{50} \max / \mathrm{IC}_{50} \min [$ here]. 


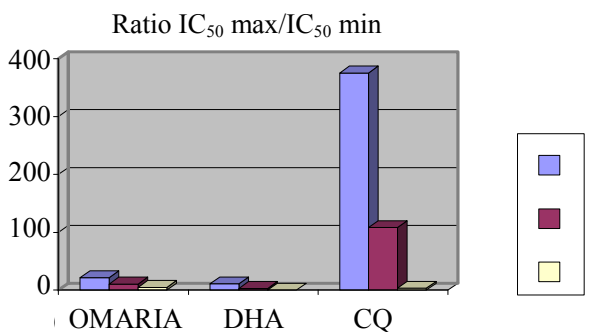

Figure 5. Comparative drug dose efficacy.

whereas DHA \& CQ are pure compounds) posits as an excellent candidate even vis-à-vis drug-dose-efficacy parameters, also. DHA has a ultra short plasma life with least possibility of therapeutic use in hemoparacytosis.

\section{Discussions}

To overcome the problem of antimalarial drug resistance, some new antimalarial compounds are needed. In this way, traditional medicine represents a good alternative. The use of Punica granatum as an anti-malarial along with the use of suggestive applied terms (viz. feverobstinate/recurrent/cyclic fever or pyrexia types) is not noted in traditional therapeutic literature of the Nipponese; Maori; South and Central American; Egyptian; Grecian; Latin; Negroid; Unani; Arabian; Bactrian; Scandinavian; Homeopathy; etc., ancient cum medieval schools of non-invasive medicine including Ayurveda [27-29]; the Sino-Mongoloids [30] and Modern Indian Medicinal sciences and their European sources [31].

Anthropologists have often opined about underlying commonality between the native (tribal) Indian and African anthropogenic stocks. Relevantly, OMARIA has all along followed a "Bottom-Up" model (extensively incorporates native tribal body-mass), and that such models are considered as more useful from the perspective of economic status of the Afro-Asian-Latin American nations, and in new drug development.

World wide, there are three types of Punica. 1) Pomegranate, on ripening becomes leathery reddish brown, grows normally in the temperate and semi temperate climates. It is known as Bedana in Sanskrit and in many other Indian vernaculars; 2) Dalimba, commercial grade, is a lesser species of Pomegranate/Bedana; is of same size, yellows on ripening, cultivated seasonally in deciduous conditions; also tropical. No. $1 \& 2$ have thin rinds and other limitations; 3) Dalimba (small) is native to India (Figure 3 and 4); is grown in kitchen gardens, is year round fruiting. It has thick rind and only therapeutic value and no commercial fruit or food value. OMARIA is a sterling new find and merits validation under challenging clinical conditions of the African fields.

In the way to validate the use of OMARIA (ethanolic extracts at Franceville, Gabon), we found that, OMARIA is highly selectively active against $P$. falciparum CQ resistant and CQ sensitive strains. This activity is consistent with previous data observed in Cuba where $P$. granatum exhibited a SI of around 10 [32] and with antiplasmodial activity of methanolic extracts of this plants (see Ref $[13,14])$. Because, methanolic extracts are less selective than ethanolic extracts our result suggest an acceptable Index (SI) and the suitability (relevance) of such extraction from OMARIA. Similarly, clinicians will always prefer a drug that will indicate least swing range (Table 3). The wider the swing, the more variable (uncertain) is the clinical efficacy and result; and the dosetherapy ratio stands the risk of going askew.

OMARIA is almost uniformly potent against all drug resistant and drug sensitive isolates. It indicates that the mechanism of action of OMARIA is different from the drug action mechanisms of CQ and artémisinine and its derivates. Furthermore, antiplasmodial activity of OMARIA is not impeded by Pfmdr1 N86 genotypes. In other words, OMARIA yields consistent results irrespective of drug resistant status of the field isolates. Even in the case of OMARIA, all responses are individual specific - which is in consonance with general pharmacological performance at clinical level (historically, world wide). This suggest that OMARIA can be one of potential drugs alternatively.

DHA is now the best antimalarial drug but some result indicated the emergence of $P$. falciparum resistance with the decrease of parasite clearance [33]. We found that one isolate has an $\mathrm{IC}_{50}$ higher that $10 \mathrm{nM}$ with $\mathrm{DHA}$, confirming previous data showing that Franceville is region with the high level of isolates having higher $\mathrm{IC}_{50}$ with DHA (JB Lekana-Douki unpublished data). So, there is no linearity between CQ and DHA as regards potency/ sensitivity $v i s-\grave{a}$-vis any isolate. In other words, non-linear, (even stark) variability is the hall mark of our sample isolate group (individual specific).

OMARIA is very effective against drug resistant African field isolates (cross continental efficacy). Even against the Pfmdr1 $86 \mathrm{~N}$ genotype that is a candidate of Artemether-Lumefantrine resistance. Offers minimum swing across the isolate's resistance spectrum (better than DHA). Posits for possible: 1) use in pregnancy; 2) bolus use; 3) small doses; 4) SOS/brain malaria; 5) prophylaxis in post surgical/cadaver transplant cases and for therapeutics in concurrent/opportunistic infestations; 6) concurrent use with DHA as a rapid acting hyper potent anti-Brain malaria (status neuro-muscular morbidity) single-shot drug; 7) in the making of a new series of semi-synthetic and synthetic drugs. This is the first such validation of OMARIA in clinical conditions, outside India. While invest- 
ments and search for newer \& better anti-malarials will (surely) continue, one may consider to Fight Malaria at Home, with OMARIA. The next step will be the clinical trials in different African endemic areas and comparisons with African parables.

\section{Acknowledgements}

This work is part attainment of the objectives as enshrined in the bi-lateral agreement between the Indian and the Gabonese workers as signed on 06-11-2008 (herein the authors). We are grateful to the children and their parents who accepted to participate in the study, and to the staff of the pediatric wards (particularly Dr Okagna and Dr Ekaghba, Patrician, Michel and Tiburce of LAM of Centre Hospitalier Régional Amissa Bongo and Hôpital de l'Amitié Sino-Gabonaise, Franceville. We also thank the staff of the Medical Parasitology Unit at Centre International de Recherches Médicales de Franceville (CIRMF) which is sponsored by TOTAL ${ }^{\circledR}$.

\section{REFERENCES}

[1] WHO, "Global Malaria Report," 2010.

[2] P. K. Loren Veronic, "Malaria Vaccine: Looking Back and Lessons Learnt," Asian Pacific Journal of Tropical Biomedicine, Vol. 1, 2011, pp. 78-79. doi:10.1016/S2221-1691(11)60072-5

[3] S.Turschner and T. Efferth, "Drug Resistance in Plasmodium: Natural Products in the Fight against Malaria," Mini Review in Medicical Chemistry, Vol. 9, No. 2, 2009, pp. 206-214. doi:10.2174/138955709787316074

[4] S. C. Chhabra, B. L. A. Mahunnah and E. N. Mshiu, "Plants Used in Traditional Medicine in Eastern Tanzania. I. Pteridophytes and Angiosperms (Acanthaceae to Canellaceae)," Journal of Ethnopharmacology, Vol. 21, No. 3, 1987, pp. 253-277. doi:10.1016/0378-8741(87)90103-6

[5] S. Schwikkard and F. R. van Heerden, "Antimalarial Activity of Plant Metabolites," Natural Product Reports, Vol. 19, No. 6, 2002, pp. 675-692. doi:10.1039/b008980j

[6] B. K. S. Yeung, B. Zou, M. Rottmann, et al., "Spirotetrahydro $\beta$-Carbolines (Spiroindolones): A New Class of Potent and Orally Efficacious Compounds for the Treatment of Malaria," Journal of Medicianl Chemistry, Vol. 53 , No. 14, 2010, pp. 5155-5164. doi:10.1021/jm100410f

[7] BBC, "India Claims Herbal Malaria Cure," 24 October 2000.

http://www.news.bbc.co.uk/2/hi/south_asia/988316.stm

[8] E. Times, "Herbal Anti-Malaria Drug on Anvil, News Report," India's National Circulation-News Paper, Calcutta, 25 October 2000, p. 6.

[9] P. Express, "Fortnightly Insight for Pharma Professionals," Pharma Express, Bombay, 2006, pp. 1-15.

[10] D. Bhattacharya, "Why Fight Malaria?" DRUG ONE
(Pharma Tabloid), Vol. 2, 2007, pp. 30-36.

[11] A. Viera, A. Maria, N. Elena, A. Jan and H. Henrieta, "Costs Analysis of the Treatment of Imported Malaria," Malaria Journal, Vol. 11, 2012. doi:10.1186/1475-2875-11-1

[12] D. Bhattacharya, "Fight Malaria at Home: Therapeutic \& Prophylaxis Clinical Data," Asian Pacific Journal of Tropical Disease, Vol. 1, No. 2, 2011, pp. 142-149.

[13] M. Dell'Agli, G. V. Galli, Y. Corbett, D. Taramelli, L. Lucantoni, A. Habluetzel, O. Maschi, D.Caruso, F. Giavarini, S. Romeo, D. Bhattacharya and E. Bosisio, "Antiplasmodial Activity of Punica granatum L. Fruit Rind," Journal of Ethnopharmacology, Vol. 125, No. 2, 2009, pp. 279-285. doi:10.1016/j.jep.2009.06.025

[14] M. Dell'Agli, G. V. Galli, M. Bulgari, N. Basilico, S. Romeo, D. Bhattacharya, D. Taramelli and E. Bosisio, "Ellagitannins of the Fruit Rind of Pomegranate (Punica granatum) Antagonize in Vitro the Host Inflammatory Response Mechanisms Involved in the Onset of Malaria," Malaria Journal, Vol. 9, No. 1, 2010, p. 208. doi:10.1186/1475-2875-9-208

[15] D. Bhattacharya, "Punica Granatum's Dermis Indicates Anti-Malarial Therapeutics \& Prophylaxis," 4th Pan African Malaria Conference, Multilateral Initiative on Malaria, Yaounde, 13-18 November 2005, pp. 195-196.

[16] M. Prato and G. Giribaldi, "Matrix Metalloproteinase-9 and Haemozoin: Wedding Rings for Human Host and Plasmodium falciparum Parasite in Complicated Malaria," Journal of Tropical Medicine, 2011, Article ID: 628435. doi: $10.1155 / 2011 / 628435$

[17] P. Deloron, J. Mayombo, A. Le Cardinal, J. Mezui-MeNdong, C. Bruzi-Baert, F. Lekoulou amd N. Elissa, "Sulfadoxine-Pyrimethamine for the Treatment of Plasmodium falciparum Malaria in Gabonese Children," Transactions of the Royal Society of Tropical Medicine and Hygiene, Vol. 94, No. 2, 2000, pp. 188-190. doi:10.1016/S0035-9203(00)90272-4

[18] J. M. Ndong, C. Atteke, A. Aubouy, M. Bakary, J. Lebibi and P. Deloron, "In Vitro Activity of Chloroquine, Quinine, Mefloquine and Halofantrine against Gabonese Isolates of Plasmodium falciparum," Tropical Medicine \& International Health, Vol. 8, No. 1, 2003, pp. 25-29. doi:10.1046/j.1365-3156.2003.00967.x

[19] J. B. Lekana-Douki, S. D. Boutamba, R. Zatra, S. E. Edou, H. Ekomy, U. Bisvigou and F. S. Toure-Ndouo, "Increased Prevalence of the Plasmodium falciparum Pfmdr1 86N Genotype among Field Isolates from Franceville, Gabon after Replacement of Chloroquine by ArtemetherLumefantrine and Artesunate-Mefloquine," Infection, Genetics and Evolution, Vol. 11, No. 2, 2011, pp. 512-517.

[20] N. Dhingra, P. Jha, V. P. Sharma, A. A. Cohen, R. M. Jotkar, P. S. Rodriguez, D. G. Bassani, W. Suraweera, R. Laxminarayan and R. Peto, "Adult and Child Malaria Mortality in India: A Nationally Representative Mortality Survey," Lancet, Vol. 376, No. 9754, 2010, pp. 1768-1774. doi:10.1016/S0140-6736(10)60831-8

[21] K. M. Prashant, J. Hema, V. Neena, K. S. Surya, E. Alex, M. B. Rajendra, C. S. Harish, L. S. Patrick, P. D. Aditya, 
K. B. Virendra, "Mutant pfcrt 'SVMNT' Haplotype and Wild Type Pfmdr1 'N86' Are Endemic in Plasmodium vivax Dominated Areas of India under High Chloroquine Exposure," Malaria Journal, Vol. 11, 2012.

doi:10.1186/1475-2875-11-16

[22] W. Trager and J. B. Jensen, "Human Malaria Parasites in Continuous Culture," Science, Vol. 193, No. 4254, 1976, pp. 673-675. doi:10.1126/science.781840

[23] J. B. Douki, Y. Sterkers, C. Lepolard, B. Traore, F. T. Costa, A. Scherf and J. Gysin, "Adhesion of Normal and Plasmodium falciparum Ring-Infected Erythrocytes to Endothelial Cells and the Placenta Involves the Rhoptry-Derived Ring Surface Protein-2," Blood, Vol. 101, No. 12, 2003, pp. 5025-5032. doi:10.1182/blood-2002-12-3710

[24] T. Planche, S. Krishna, M. Kombila, K. Engel, J. F. Faucher, E. Ngou-Milama and P. G. Kremsner, "Comparison of Methods for the Rapid Laboratory Assessment of Children with Malaria," The American Journal of Tropical Medicine and Hygiene, Vol. 65, No. 5, 2001, pp. 599602.

[25] P. Druilhe, A. Moreno, C. Blanc, P. H. Brasseur and P. Jacquier, "A Colorimetric in Vitro Drug Sensitivity Assay for Plasmodium falciparum Based on a Highly Sensitive Double-Site Lactate Dehydrogenase Antigen-Capture Enzyme-Linked Immunosorbent Assay," The American Journal of Tropical Medicine and Hygiene, Vol. 64, No. 5-6, 2001, pp. 233-241.

\section{Abbreviations}

OMARIA: Orissa Malaria Research Indigenous Attempt; DELI: Double-site enzyme-linked lactate dehydrogenase immunodetection assay; pLDH: Plasmodium Lactate De-
[26] T. Mosmann, "Rapid Colorimetric Assay for Cellular Growth and Survival: Application to Proliferation and Cytotoxicity Assays," Journal of Immunological Methods, Vol. 62, No. 1-2, 1983, pp. 55-63. doi:10.1016/0022-1759(83)90303-4

[27] Atharva Veda Samhita, "Medicine Chapter as Cited in P. Sen, 1907," Journal of the Asiatic Society, 1907, pp. 11-12.

[28] C. Samhita, "c.4th A.D., of Agnivesa," B. Tripathy, Ed. Chaukhamba Surabharati Prakashan, Varanasi, 1973, p. 2.

[29] D. G. Vigyana, "Part II, (Sanskrit; Full Book)," A. P. Sharma, Ed., Chowkhamba Bharat Academy, Varanasi, 1983.

[30] Z. D. Cidian, "Grand Dictionary of Chinese Traditional Medicine," 2nd Edition, Shanghai Science \& Technology Press, Shanghai, 2005.

[31] R. P. Rastogi, B. N. Mehrotra, S. Sinha, M. Srivastava and B. Bhusan, "Compendium of Indian Medicinal Plants," Central Drug Research Institute, Lucknow, 1986.

[32] A. F. Valdes, J. M. Martinez, R. S. Lizama, Y. G. Gaiten, D. A. Rodriguez and J. A. Payrol, "In Vitro Antimalarial Activity and Cytotoxicity of Some Selected Cuban Medicinal Plants," Revista do Instituto de Medicina Tropical de Sao Paulo, Vol. 52, No. 4, 2010, pp. 197-201. doi:10.1590/S0036-46652010000400006

[33] S. M. Taylor, J. J. Juliano and S. R. Meshnick, "Artemisinin Resistance in Plasmodium falciparum Malaria," The New England Journal of Medicine, Vol. 361, No. 18, 2009, pp. 455-467.

hydrogenase; $\mathrm{IC}_{50}$ : inhibition concentration $50 \%$, dose which inhibit growth parasite by $50 \%$; $\mathrm{LD}_{50}$ : Lethal dose $50 \%$, dose which inhibit growth human cells by $50 \%$. 